\title{
AS FOLHAS DE VIDEIRAS DAS EVAS DA ILHA DE MARAJÓ E A (DES)CONSTRUÇÃO DE NARRATIVAS ARQUEOLÓGICAS
}

\section{RESUMO}

A teoria queer tem possibilitado uma auto-reflexão à Arqueologia sobre a maneira como constrói a sua definição sobre o "outro" do passado a partir do espelhamento de valores e conceitos hegêmonicos. Diante disto, interpretações cisheteronormativas sobre as sociedades pretéritas têm sido questionadas, visando construir maneiras alternativas de representar o passado, sobretudo, no que diz respeito a gênero e sexualidade.

Interpretações arqueológicas têm sugerido, desde a segunda metade do século XIX, que as tangas de cerâmica da fase marajoara eram usadas exclusivamente por mulheres e isto tem sido reproduzido até os dias de hoje. Este artigo revisita, a partir da crítica da Arqueologia Queer, a bibliografia referente às tangas cerâmicas com o intuito de compreender como esta ideia foi desenvolvida, visando também confrontar os dados contextuais disponíveis.

PALAVRAS-CHAVE: Fase Marajoara, Tangas cerâmicas, Arqueologia Queer, enviesamento da interpretação arqueológica

\begin{abstract}
Queer theory has enabled Archaeology to reflect upon how it constructs its definition of the "other" of the past by mirroring hegemonic values and concepts. In view of this, cis heteronormative interpretations of past societies have been questioned in order to construct alternative ways of representing the past, especially with respect to gender and sexuality. Since the second half of the nineteenth century, archaeological interpretations of the ceramic tangas of the Marajoara phase have suggested that they were used exclusively by women, a view that has been reproduced to this day. This article revises, from the Queer Archaeology critique, the bibliography referring to the ceramic tangas in order to understand how this idea was formed, and confronts the contextual data available.
\end{abstract}

KEYWORDS: Marajoara Phase, Ceramic tangas, Queer Archeology, Bias of Archaeological Interpretation

\section{RESUMEN}

La teoría queer ha posibilitado una auto-reflexión al interior de la Arqueología sobre la forma en que construye su definición sobre el "otro" del pasado a partir del reflejo de valores y conceptos hegemónicos. En este sentido, hoy en dia las interpretaciones sobre las sociedades pretéritas han sido cuestionadas, intentando construir formas alternativas de representar el pasado, sobre todo, en lo que se refiere al género y la sexualidad. Las interpretaciones arqueológicas han sugerido, desde la segunda mitad del siglo XIX, que las tangas de cerámica de la fase Marajoara eran usadas exclusivamente por mujeres y esto ha sido reproducido hasta los días de hoy. Este artículo revisita, a partir de una óptica crítica derivada de la Arqueología Queer, la bibliografía referente a las tangas cerámicas con el

1 Doutorando, Museu de Arqueologia e Etnologia/ Universidade de São Paulo.

\begin{tabular}{|l|l|l|l|l|l|l|}
\hline (C) Rev. Arqueologia Pública & Campinas, SP & v.13 & n.1 & p. & Jul/2019 & ISSN 2237-8294
\end{tabular}


objetivo de comprender cómo se formuló esta idea, buscando también confrontar los datos contextuales disponibles.

PALABRAS CLAVE: Fase Marajoara, Tangas cerámicas, Arqueología Queer, sesgo de la interpretación arqueológica

\title{
INTRODUÇÃO
}

\begin{abstract}
Mas as interpretações heteronormativas dos achados arqueológicos nunca são sustentadas por evidências de qualidade. Penso que o primeiro passo é questionarmos rigorosamente e eliminarmos as interpretações supérfluas e infundadas de gênero e sexualidade. Precisamos desafiar nossos colegas quando eles usam estereótipos para fazer atribuições de gênero. E, só então, quando pararmos de sobrepor estereótipos de gênero e de sexo às evidências arqueológicas, seremos capazes de desenvolver metodologias reais que investiguem de fato a sexualidade, em vez de presumi-la (VOSS apud WICHES et al 2018, p.196).
\end{abstract}

Em uma recente entrevista concedida à revista Habitus (WICHERS et al 2018), Barbara Voss chama a atenção à forma como os arqueólogos fazem interpretações sobre gênero e sexualidade nas sociedades pré-históricas. Voss destaca que para avançar um maior conhecimento do passado é necessário abandonar noções estereotipadas sobre gêneros e sexualidade.

A crítica de Voss está centrada em argumentos sobre a naturalidade da heterossexualidade e, principalmente, em como a Arqueologia contribuiu com tal naturalização ao reforçar noções sobre o passado que reproduzem normas sexuais hegêmonicas que incluem, por exemplo, o homem como caçador, a mulher como coletora, pontas de projéteis associadas a homens, pedras de moagem relacionadas a mulheres e, ainda, hipóteses de que o cerne das famílias eram casais heterossexuais (WICHERS et al, 2018, p. 195-196). Isto vai de encontro às preocupações de diversos autores que têm questionado as interpretações heteronormativas em Arqueologia e que têm trazido à tona novas formas de se aprender sobre gênero e sexualidades do passado, seja compreendendo o gênero em termos não normativos a partir de abordagens feministas na Bioarqueologia (GELLER, 2009), seja criticando interpretações iconográficas carregadas de preconceito cisheteronormativo que partem da premissa de uma estrutura social baseada 
no binarismo sexual, onde as relações são exclusivamente heterossexuais (UGALDE, 2018), seja ainda, demonstrando que o binômio macho/ fêmea nem sempre foi uma "medida natural" para classificar os corpos, como se observa, por exemplo, em representações antigas de corpos, onde os genitais não definem identidades corporais (ALBERTI, 1999).

Por trás destas críticas e reflexões estão certos incômodos surgidos no cerne da própria disciplina arqueológica ainda na década 1980, sobretudo, na Arqueologia PósProcessual, referentes à neutralidade da Arqueologia e do enviesamento das suas interpretações (HODDER, 2008; SHANKS, 2008; TILEY e SHANKS, 1987). Alertava-se desde então que o passado é construído no presente e o conhecimento sobre ele é uma interpretação feita no presente e, portanto, a disciplina não pode ser vista como um mecanismo neutro de produção de conhecimento do passado por que a interpretação é oferecida com base na expertise dos arqueólogos, estando sempre sujeita a distorções por valores e atitudes contemporâneos (SHANKS, 2008:137).

Com isto em vista, é possível interpretar o passado sem o sujeitarmos aos preconceitos cisheteronormativo que permeiam o nosso cotidiano? Para Aimers e Rutecki (2016) é preciso aplicar perspectivas críticas às nossas interpretações sobre as pessoas do passado no que diz respeito a sexo, gênero e sexualidade, pois somente desta maneira estaremos aptos a construir representações mais completas e diversificadas das populações pretéritas.

Perspectivas críticas às interpretações enviesadas visam construir maneiras alternativas de representar o passado, questionando, assim, a normatividade, o essencialismo das identidades e a estabilidade das ordens de gênero e sexualidade, desafiando, deste modo, não somente o sexismo, mas também a heteronormatividade e a prática normativa hegemônica (GONTIJO e SCHAAN, 2017). Estas abordagens têm sido inspiradas na teoria Queer, principalmente, em argumentos da filósofa pós-estruturalista Judith Butler (2013).

A teoria queer tem criticado o binarismo sexual e de gênero, propondo ao mesmo tempo desconstruí-lo e subvertê-lo (GONTIJO e SCHAAN, 2017; POMBO, 2017). Judith Butler (2013), por exemplo, defende que a categoria sexo e sua consequentemente divisão binária é uma construção social. Ao mesmo tempo, alerta que a ideia de heterossexualidade 
como predisposição natural e prática sexual comum a todos os indivíduos também é produzida socialmente. Assim como a divisão binária dos sexos, a heterossexualidade é um regime político, um dispositivo, uma instituição. A partir do argumento de Foucault (2007) de que a sexualidade é construída nas redes do discurso e do poder, a autora propõe que o poder deve ser compreendido em termos das convenções culturais heterossexuais e fálicas, ou seja, em termos de uma matriz binária heterossexual que estabelece simultaneamente uma hierarquia entre masculino e feminino, e uma heterossexualidade compulsória e naturalizada. A partir destes argumentos, em Arqueologia, a teoria queer pode então ser utilizada enquanto um mecanismo de contestação das interpretações normativas e heteronormativas (GONTIJO e SCHAAN, 2017).

Neste artigo se pretende problematizar a ideia de que as tangas cerâmicas da fase marajoara eram objetos usados exclusivamente por mulheres. As tangas despertam a atenção dos pesquisadores desde que os sítios da fase marajoara passaram a ser explorados, ainda no início da década de 1870. E desde então diversos autores dedicaram especial atenção ao seu estudo. Estes estudos têm sido norteados por duas perguntas: por quem e para que as tangas eram usadas e qual era o significado dos seus grafismos? Aqui, se pretende focar, particularmente, em como a Arqueologia tem respondido à primeira pergunta, isto é, por quem e para que as tangas eram usadas, mas, especialmente, nos pressupostos que as associam a pessoas do sexo feminino. Para tanto, a teoria queer, aqui, é utilizada como uma lente analítica, tanto para revisitar os textos em que esta ideia foi construída, quanto para revisitar os dados disponíveis atualmente no que diz respeito aos contextos funerários das tangas.

\section{AS TANGAS CERÂMICAS MARAJOARA}

Os objetos cerâmicos provenientes dos sítios arqueológicos da fase marajoara² despertaram a atenção dos pesquisadores na segunda metade do século XIX quando os

\footnotetext{
${ }^{2}$ A fase marajoara é um período de ocupação da llha de Marajó, descrito primeiramente por Meggers (1954) e Meggers e Evans (1957), atrelado às culturas estabelecidas ali, entre 400 e 1300 AD, sobretudo, na sua porção leste, e que ocuparam uma área de, aproximadamente, 20 mil quilômetros quadrados (Roosevelt, 1991; Schaan, 2004). Os aterros, conhecidos como "tesos", construídos para fins funerários, rituais e de habitação (Roosevelt, op.cit.; Schaan, op.cit.), assim como as cerâmicas, elaboradas por uma gama de técnicas decorativas, tais como, incisão, excisão, pintura, modelado, etc. são as características definidoras mais emblemáticas desta fase (Barreto, 2009; Meggers e Evans, 1957; Roosevelt, 1991.; Schaan, 2004).
}

\begin{tabular}{|l|l|}
\hline (c) Rev. Arqueologia Pública & Campinas, SP \\
\hline
\end{tabular}

\begin{tabular}{|l|l|l|l}
\hline v.13 & n.1 \\
\hline
\end{tabular}

p.

$\mathrm{Jul} / 2019$

ISSN 2237-8294 
tesos passaram a ser explorados para obtenção de coleções para diversos museus (FERREIRA PENNA, 1877; HARTT, 1871, 1876, 1885; NETTO, 1885). A diversidade de objetos cerâmicos, caracterizados por uma miríade de morfologias e formas de decoração, associada aos contextos funerários e de construção da paisagem, ao longo das décadas, deu origem a diversas teorias sobre complexidade social e sobre o uso do estilo e iconografia cerâmicos em estratégias de legitimação de poder por elites sociais (MEGGERS e EVANS, 1957; ROOSEVELT, 1988, 1991; SCHAAN, 2001a, 2001b, 2003, 2004), bem como sobre identidades e papel de gênero (BARRETO, 2004; ROOSEVELT, op.cit; SCHAAN, 2001a, 2001b, 2003).

As tangas cerâmicas são alguns dos objetos mais emblemáticos da fase marajoara, caracterizadas pela variabilidade em relação ao tratamento cromático de sua superfície, morfologias e tamanhos (ver figura 1). Elas, juntamente com as urnas funerárias e estatuetas cerâmicas, são frequentemente citadas em estudos sobre identidades e papel de gênero no Marajó antigo (BARRETO, 2004; SCHAAN, 2001a, 2001b), sendo quase um consenso entre os arqueólogos de que o seu uso em contexto sistêmico era destinado exclusivamente às mulheres (BARATA, 1968; BARRETO, 2004; FIGUEIREDO, 1956; HARTT, 1876; MORDINI, 1929; NETTO, 1885; PROUS, 2013; PROUS e LIMA, 2011; RODRIGUES et al, 2011; SCHAAN, op.cit.).

A maior peculiaridade das tangas é terem sido fabricadas de argila, além disto, possuem o formato triangular convexo e têm orifícios em suas extremidades por onde eram passados cordões para prendê-las ao corpo, sendo que o atrito destes produziu marcas de desgaste nestas extremidades. Ademais, há pelo menos três morfologias registradas que se apresentam mais ou menos padronizadas em relação ao seu tamanho e à sua curvatura (MEGGERS E EVANS, 1957; NOBRE, 2017; PROUS E LIMA, 2011; SCHAAN, 1997, 2003). Em relação ao tratamento de suas superfícies, podem ser apenas engobados de vermelho ou de alaranjado ou de marrom ou de preto, e em alguns casos, cobertas com uma dupla camada de tinta, sendo a primeira de cor vermelha e a segunda camada preta ou marrom, e ainda podem apresentar a sua superfície ornada com grafismos pintados em vermelho ou marrom ou preto sobre um engobo de cor clara que pode variar entre o branco, o creme e o alaranjado (NOBRE, 2017). 


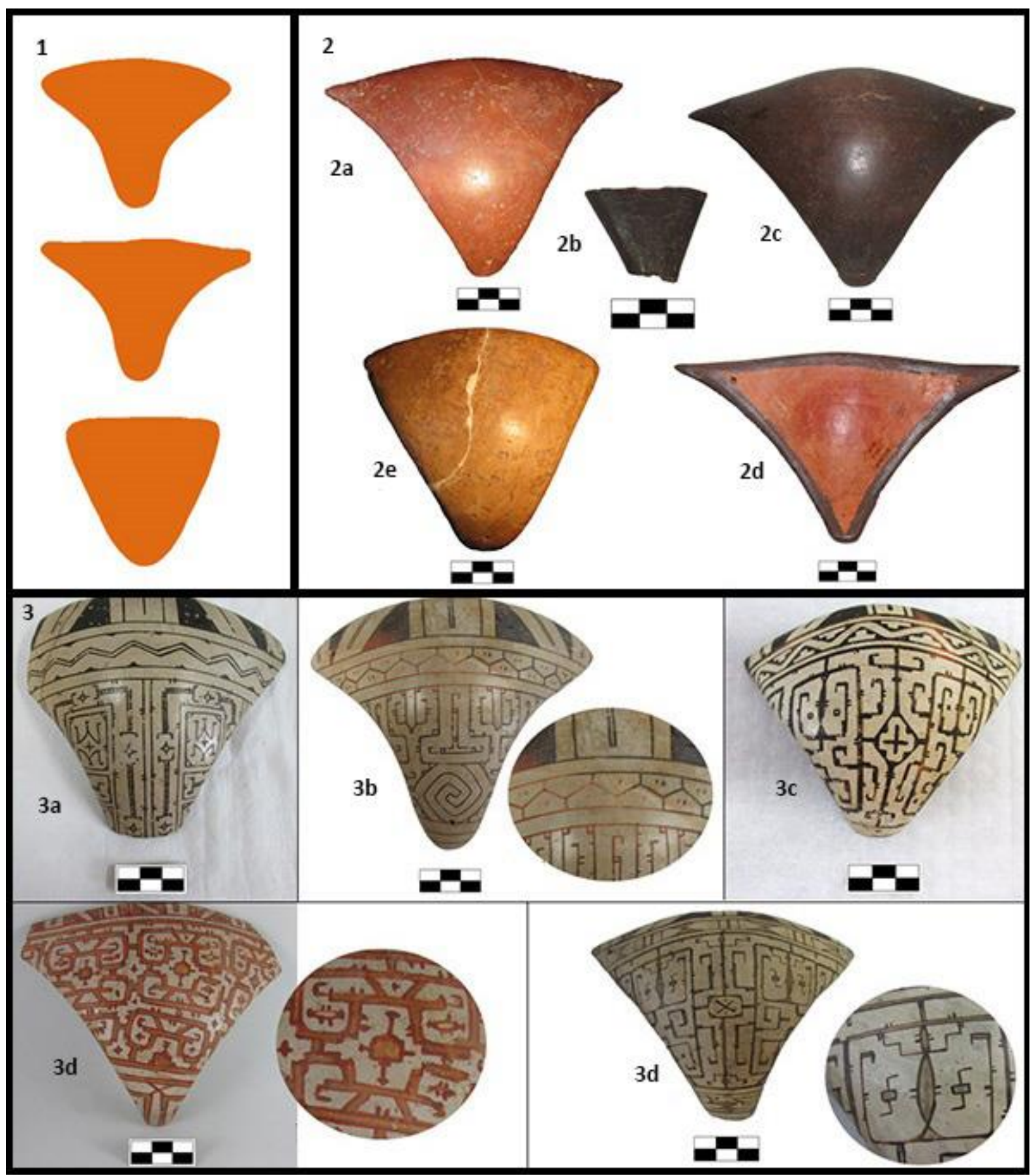

Figura 1. Variabilidade das tangas em relação às suas morfologias, tamanhos e tipo de tratamento cromático da sua superfície.

1. Variabilidade de morfologias das tangas

2. Variabilidade cromática das tangas monocromáticas.

2a. Tanga com engobo vermelho. Antigo Instituto Cultural Banco Santos/ MAE-USP, São Paulo.

2b. Fragmento com engobo na cor preta nas duas faces. Museu de Arqueologia e Etnologia IUSP, São Paulo.

2c/2d. Tanga coberta com dupla camada de engobo marrom escuro sobre vermelho. Antigo Instituto Cultural Banco Santos/ MAE-USP, São Paulo.

2e. Tanga engobada de amarelo-alaranjado. Museu Paraense Emilio Goeldi/MCTI, Belém. 
3. Variação cromática das tangas com grafismos

3a.. Tanga apresentando grafismos pretos sobre engobo creme. Museu Nacional, Rio de Janeiro.

3b. Tanga com grafismos marrons apresentando áreas mais claras em vermelho. Museu Nacional, Rio de Janeiro.

3c. Tanga com grafismos marrons escuros sobre branco. Coleção Oliveira. Museu do Estado de Pernambuco, Recife.

3d. Tanga com grafismos vermelho com áreas preenchidas por tinta laranja sobre creme. ICBS/MAE-USP, São Paulo.

3e. Tanga com grafismos marrons com áreas preenchidas por tinta marrom diluída. Museu do Estado de Pernambuco, Recife.

As características formais acima mencionadas têm sido utilizadas, há quase um século e meio, para sugerir que as tangas foram objetos confeccionados para serem utilizados por pessoas do sexo feminino. Hartt (1976: 22), por exemplo, conjectura que a sua forma triangular e o tamanho, a direção dos desgastes dos seus orifícios, a ornamentação delicada de sua superfície seriam um reflexo do uso por mulheres das tangas. $^{3}$

Nas próximas seções se pretende demonstrar criticamente como, ao longo deste tempo, diferentes autores presumiram um uso exclusivamente feminino às tangas. Para tanto, a discussão a seguir será apresentada em ordem cronológica, considerando desde as primeiras alegações, no fim do século XIX, até os estudos mais recentes.

\section{AS FOLHAS DE VINHAS DAS EVAS E DAS MORENAS INSULARES}

O primeiro registro das tangas foi feito por Charles Hartt em 1871, em um artigo, na American Naturalist, que anunciava ao mundo a descoberta da cerâmica marajoara. Até então, só haviam sido descobertos alguns fragmentos, o que dificultava a identificação das peças, no entanto, Hartt sugeria a possibilidade de que fossem fragmentos de colheres. Poucos anos mais tarde, no entanto, o autor já parecia ter certeza de que se tratava de tangas usadas por mulheres (HARTT, 1876: 22).

3 Vale lembrar que em estudos iconográficos, ainda hoje, as representações de triângulos são vistas
como uma alusão ao delta púbico feminino, sobretudo, quando acompanhadas de características
como ventre projetado, seios fartos, nádegas salientes, etc. (Cardoso, 1995; Conkey, 1989; Marqueti e Funari, 2011). 
Quase uma década mais tarde, em 1885, Ladislau Netto, na época, diretor do Museu Nacional do Rio de Janeiro, publicou "Investigações sobre a Archeologia brazileira", texto em que descrevia e interpretava várias categorias de objetos cerâmicos presentes nas coleções do Museu Nacional do Rio de Janeiro, a maioria proveniente da llha do Marajó.

Neste texto, a primeira menção às tangas é: "Chamo-Ihes adornos, porque eram, segundo penso, o único objecto com que as morenas insulares procuravam velar a sua nudez" (NETTO, 1885, p. 433-434). Algumas páginas à frente o autor segue afirmando que "os formosíssimos ornatos que serviam de Folium vitis às Evas de Marajó sempre os encontrei dentro das urnas em que haviam sido depositadas ossadas de mulher" (NETTO, 1885, p. 339). Assim, é possível notar dois aspectos recorrentes: o primeiro deles diz respeito à generalização de que tangas jaziam sempre depositadas em urnas com vestígios ossos de mulheres; o segundo se relaciona à associação das tangas a folhas de videiras ou folium vitis, além do uso de uma série de adjetivos para se referir às supostas mulheres que as usavam, como "Evas e morenas insulares", o que sugere uma idealização das mulheres indígenas do passado pré-colonial comparando-as à Evas vivendo em um estado de pureza em um paraíso.

Por ora, segue-se priorizando o primeiro aspecto. Seguindo a sua interpretação das cerâmicas de Marajó, algumas páginas à frente, Netto faz a seguinte afirmação: "Os mounds de Marajó só nos hão podido legar alguns fragmentos de craneos, tão adiantada foi a decomposição dos ossos, ainda que sob o resguardo das urnas em que se achavam" (NETTO, 1885, p. 400). Algumas páginas antes o autor registrou que "todas as urnas em que se guardaram ossos de mulher, hão sempre apresentado, de permeio com os fragmentos quasi pulverisados dos mesmos ossos ou com a terra que os envolve, aquella singular espécie de Folium vitis" (NETTO, 1885: 432). Netto (1885) não menciona qualquer tipo de análise nos poucos fragmentos ósseos provenientes dos sepultamentos. Aliás, as primeiras análises em vestígios ósseos provenientes de sepultamentos da fase marajoara só foram registradas quase 70 anos mais tarde, na década de 1950, no âmbito da pesquisa

\footnotetext{
${ }^{4}$ É importante destacar também que no artigo escrito por Hartt sobre as tangas, em 1876, há uma nota de rodapé escrita por Landislau Netto, à época redator dos Archivos do Museu Nacional do Rio de Janeiro, onde indaga qual seria o nome nativo dado às tangas e ali há também outros adjetivos usados para se referir às mulheres que as usavam. Assim segue parte da nota: "É a folha da videira das antigas Evas do Marajó. O segredo do seu nome guarda n'o para sempre, como as urnas dos perfumes das virgens morenas dos tupys, as areias mudas da grande ilha" (Hartt, 1976: 21).
}

\begin{tabular}{|l|l|l|l|l|l|l|}
\hline (c) Rev. Arqueologia Pública & Campinas, SP & v.13 & n.1 & p. & Jul/2019 & ISSN 2237-8294 \\
\hline
\end{tabular} 
de Betty Meggers e Clifford Evans (1957). Como então Netto (1885) presumiu a relação entre mulher/ ossos de mulher e tangas?

Algumas características iconográficas tiveram um papel crítico na consolidação desta ideia como alguns autores deixam claro (HARTT, 1885; MORDINI, 1929; NETTO, 1885). Na mesma época, em Santarém, foi descoberta uma estatueta com características femininas, cuja região pubiana era demarcada pelo desenho de um triângulo feito em incisão, e que, alguns autores da época, como Charles Hartt (1885: 51; 56), viam como a representação de uma tanga ${ }^{5}$.

Além disto, alguns tipos de urnas funerárias, onde algumas tangas haviam sido depositadas, eram vistas como representações de mulheres, como é o caso das urnas do estilo Pacoval (ver figura 3c). Ferreira Penna (1877: 57-58), ao descrever uma destas urnas, por exemplo, ressalta alguns possíveis atributos femininos presentes nela, como por exemplo, mamilos ${ }^{6}$ e uma tanga entre os membros inferiores. Deste modo, se pensava que havia uma correspondência entre certas características das pessoas sepultadas, como por exemplo, o sexo, e as características iconográficas das urnas (NETTO, 1885: 326), e por esta razão se presumia que as urnas com características supostamente femininas continham ossos de mulheres em seu interior, e a partir disto inferiu-se que as tangas por estarem associadas a estas urnas também eram femininas.

Tais interpretações refletiam um cenário mais amplo que buscava formatar uma identidade nacional com base na figura bastante idealizada do indígena e, principalmente, da mulher indígena e do seu corpo. Este cenário se refletia para além da Arqueologia do fim do século XIX, tendo sido materializado, sobretudo, pelas artes plásticas e pela literatura. As idealizações ressaltavam, sobretudo, a figura da mulher indígena, enfatizando a sua beleza e inocência e o seu caráter puro e majestoso, sua virgindade e a sua sensualidade, a exemplo, da figura fictícia de Iracema, cuja beleza exótica e sensualidade

5 Para barata (1968) esta afirmação não faz o menor sentido, primeiramente, porque as tangas cerâmicas são peculiares ao Marajó, e também porque triângulos desenhados por meio de incisão é uma característica comum na cerâmica de Santarém para a representação da genitália feminina.

$6 \quad$ No que diz respeito à representação dos mamilos, são conhecidas várias urnas funerárias provenientes de várias regiões da Amazônia que possuem representações de mamilos e pênis, a exemplo das urnas Policromas, do Médio Amazonas, e das urnas Maracá e Caviana, provenientes do sul e sudeste do Amapá, mostrando, assim, que nem sempre mamilos são atributos unicamente femininos. 
foram idealizadas, por de José de Alencar, sob o epíteto de "a virgem dos lábios de mel" (SILVA e CORREIA, 2017).

Nas artes plásticas, a mulher era representada quase sempre como uma Eva, nua ou semi-nua, caracterizada por um corpo sinuoso, provocativo, com contornos opulentos e sedutores, seios redondos e grandes (ver figura 2), "em plena nudez, deixando ver a descoberto as mil bellezas, os mil segredos que ella não teme desvendar" (GAZETA DA TARDE, 24 de agosto de 1884 apud Silva 2007, p.66). Na Arqueologia, as tangas foram também idealizadas como as "folhas de videira" que cobriam o corpo das "morenas insulares", das "Evas de Marajó" (NETTO, 1895), ou seja, refletiam a ideia de sensualidade e pureza da mulher indígena do passado. 

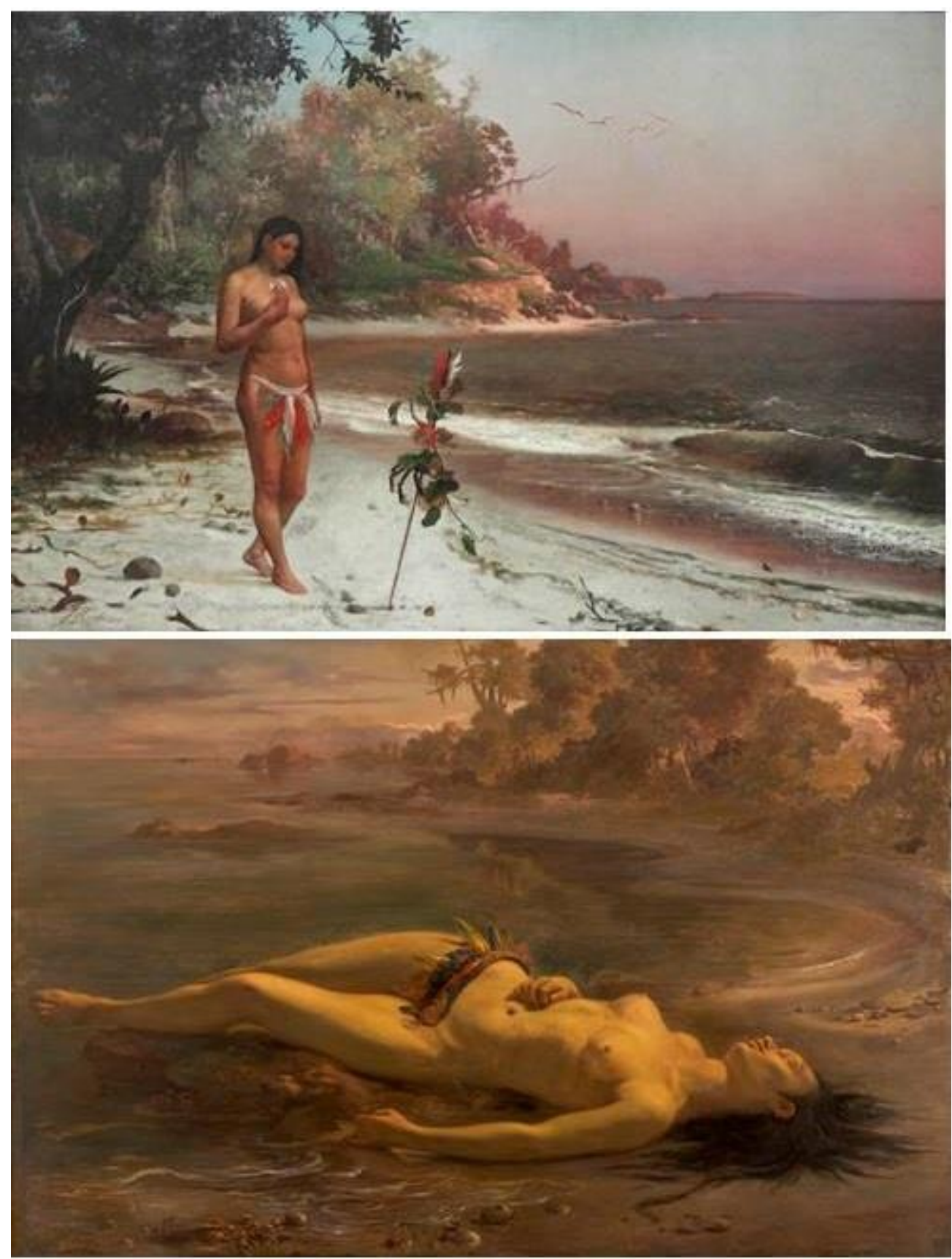

Figura 2. Pinturas indianistas que ressaltam a idealização do corpo da mulher indígena durante 0 período. Destaque, sobretudo, à forma de representação que frisa corpos sinuosos, provocativos, contornos opulentos e sedutores.

Superior. Iracema. José Maria de Medeiros. Museu Nacional de Belas Artes, 1881.

Fonte: commons. wikimedia.org

Inferior. Moema. Victor Meirelles. Museu de Arte de São Paulo, 1866.

Fonte: commons.wikimedia.org 


\section{DADOS PLÁSTICOS E INTERPRETAÇÕES ARQUEOLÓGICAS}

Embora, após Hartt $(1876,1885)$ e Netto (1885), várias pesquisas sobre as tangas tenham sido realizadas (por exemplo, por FIGUEIREDO, 1956; MEGGERS e EVANS, 1957; MORDINI, 1929; PALMATARY, 1950), aquelas mais substanciais foram publicadas pouco mais de um século após, por Schaan (2001, 2003, 2004), com base em suas escavações no Marajó, no início da década de 2000, e também considerando mais de um século de registros e descrições de contextos até então disponíveis.

Com base nisto, a autora concluiu que as tangas seriam destinadas às mulheres da elite marajoara ${ }^{7}$. Além disto, as diferenças observadas em relação às suas características foram associadas a diferenças de idade e status social das mulheres (SCHAAN, 2003, 2004). As tangas monocromáticas teriam uma curvatura maior do que aquelas com grafismos, e seriam também mais frequentes em sepultamentos realizados em grandes urnas funerárias profusamente decoradas, o que estaria relacionado ao um uso específico por mulheres mais velhas. As tangas com grafismos, com uma curvatura menor, teriam sido usadas por mulheres mais jovens, cuja identidade e status não haviam ainda sidos firmados, durante rituais de iniciação. Nelas haveria toda uma iconografia relacionada à mulher e ao seu papel na sociedade. Os seus diferentes campos gráficos trariam informes abrangentes sobre gênero, idade, identidades individuais e sobre o papel da mulher (SCHAAN, 2001, 2003).

Esta hipótese foi elaborada com base na sugestão de Meggers e Evans (1957, p.383) de que as dimensões e a curvatura das tangas monocromáticas são maiores do que naquelas com grafismos (SCHAAN, 2003, p. 36). É importante ponderar, no entanto, que Meggers e Evans (1957) basearam as suas conclusões em poucas peças, sendo seis monocromáticas e seis com grafismos. A análise destes autores contemplou peças bastante homogêneas, em relação às morfologias e ao tipo de decoração. As seis tangas monocromáticas, com exceção de uma, eram todas peças mais compridas, com as

7 Schaan (2004) propõe, em seu modelo para explicar o desenvolvimento regional durante a fase marajoara, que grupos familiares teriam construído barragens e lagos artificiais junto às áreas de concentração dos recursos aquáticos com o fim de otimizar a captura de peixes ao fim da estação das chuvas, o que teria incrementado a oferta de recursos e gerado excedentes, propulsionando a criação de mecanismos para o seu controle, levando, por seu turno, à estratificação social. Diante disto, os grupos familiares teriam aumentado o seu poder, por meio do controle ao acesso dos recursos, o que teria sido justificado por meio de um sistema ritualístico-religioso de legitimação estruturado no parentesco com os ancestrais míticos.

\begin{tabular}{|l|l|l|l|l|l|l|l}
\hline (C) Rev. Arqueologia Pública & Campinas, SP & v.13 & n.1 & p. & Jul/2019 & ISSN 2237-8294
\end{tabular}


extremidades laterais mais pontudas e maior curvatura, enquanto que as seis tangas com grafismos eram todas de uma morfologia específica associada a dimensões menores (MEGGERS e EVANS, 1957). As tangas analisadas eram todas provenientes da região do rio Anajás, no entanto, as outras coleções provenientes dos mesmos sítios, mostram uma heterogeneidade maior e abrangem peças tanto monocromáticas, quanto com grafismos.

Mais recentemente, Prous e Lima (2011, p. 249) analisaram algumas coleções e perceberam que $36 \%$ das tangas com grafismos analisadas eram maiores, enquanto que $57 \%$ das tangas monocromáticas possuíam dimensões mais reduzidas. Estes autores ponderam que talvez não necessariamente existisse uma relação fixa entre o tipo de decoração da tanga e o seu tamanho e curvatura, já que isto poderia variar de um sítio para outro ou mesmo variar cronologicamente.

A interpretação de Schaan (2003) valeu-se também da associação entre urnas antropomorfas profusamente decoradas e tangas em seu interior. Tais urnas, segundo a autora, estariam sempre associadas a tangas e remanescentes femininos, apresentando uma diversidade de símbolos relacionados ao feminino, como fecundidade, maternidade e renascimento (SCHAAN, 2003). Segundo a autora, a conclusão de que tangas eram usadas por mulheres se baseia em dados iconográficos, em dados referentes à identificação do sexo de vestígios ósseos associados a tangas e também na analogia etnográfica (SCHAAN, 2003).

É importante destacar que durante as suas pesquisas no teso Belém, na região do Rio camutins, Schaan (2004) escavou 24 urnas funerárias, das quais seis possuíam tangas em seu interior, em um total de seis, duas vermelhas e quatro alaranjadas. No entanto, os vestígios ósseos associados às tangas, depositado nestas seis urnas funerárias, não puderam ter o sexo estimado devido à sua fragmentação intensa ou à sua má preservação (SCHAAN, 2004, p. 235-253).

Diante disto, para sustentar a sua hipótese, incorporou algumas interpretações de Meggers e Evans (1957) que haviam escavado uma grande urna contendo ossos com traços de tinta vermelha associados a uma tanga alaranjada. As análises osteológicas destes vestígios não puderam estimar o seu sexo, mas mostraram que se tratava de uma pessoa de ossos pequenos e leves, o que representaria um subadulto ou adulto 
(MEGGERS e EVANS, 1957: 271) ${ }^{8}$. Estes autores, porém, considerando a antiga ideia de que as tangas são um marcador da presença de mulheres em sepultamentos, conjecturaram em suas conclusões, que então o indivíduo sepultado junto a esta tanga seria do sexo feminino (MEGGERS e EVANS, 1957: 384).

Além disto, Schaan $(2003,2004)$ recorreu também à analogia etnográfica para apoiar a ideia de que as tangas eram usadas por mulheres, vendo nos tapa-sexos cerâmicos de forma oval usados durante um ritual de passagem pelas meninas púberes Chama, um grupo Pano que habita a região rio Ucayali, no Peru, um correlato etnográfico às tangas arqueológicas. Com isto definido, todo sepultamento em urna funerária com uma tanga associada, especialmente se a urna apresentasse características iconográficas tidas como femininas, foi interpretado como feminino, assim como fazia Ladislau Netto no século XIX.

Mais recentemente, André Prous e seus colaboradores (RODRIGUES et al, 2011) realizaram um estudo experimental com as tangas, visando observar a sua adaptação ao corpo feminino, bem como compreender a respeito de sua utilização em atividades variadas e sobre a suas marcas de uso. Foram usadas sete tangas, produzidas com base nas morfologias e dimensões observadas em peças arqueológicas, e também algumas que consideravam as dimensões médias das tangas arqueológicas. As peças foram experimentadas por sete mulheres, em várias posições corporais, em estado de repouso, andando ou dançando. No geral, os autores concluíram que o conforto ou desconforto em relação à adaptação das tangas ao corpo das experimentadoras poderiam estar associados às medidas das peças que, provavelmente, atendiam a padrões corporais femininos específicos. Além disto, os autores descartam o uso das peças por homens, ressaltando que as mesmas não cobriram completamente a genitália dos dois únicos experimentadores homens ou que seriam incômodas para eles.

Muitos dos argumentos que sustentam um uso feminino das tangas, ao longo das décadas, sugerem também que eram usadas em rituais de passagem, mais especificamente, rituais de puberdade (BARRETO, 2004; FIGUEIREDO, 1956; MEGGERS e EVANS, 1957; SCHAAN, 2003, 2004). Cabe ressaltar que diversos autores têm registrado

\footnotetext{
8 Neste caso, os dados sobre este sepultamento que continha uma tanga alaranjada foi usado para formular a hipótese de que tangas alaranjadas "eram reservadas para certa classe de mulheres, classe essa definida por posição genealógica e talvez também por idade” (schaan, 2003: 36).
}

\begin{tabular}{l|l|l|l|l|l|l|}
\hline (C) Rev. Arqueologia Pública & Campinas, SP & v.13 & n.1 & p. & Jul/2019 & ISSN 2237-8294
\end{tabular} 
como os rituais de passagem e, sobretudo, aqueles relacionados à puberdade, podem ser inscritos no corpo, causando estranhamento à nossa visão hegemônica ocidental referente à noção de conforto. Estes rituais podem ser traduzidos, mediante processos distintos para homens e mulheres, por uma série de atribuições que incluem, principalmente, o uso de adornos e marcas corporais, como escarificações, circuncisão, modificação do formato dos dentes, perfurações no nariz ou lábios (ALVAREZ, 2005; RANGEL, 1999; RIVIÈRE, 2013).

Os rituais femininos, por exemplo, podem incluir longos períodos de reclusão e mesmo a ablação do clitóris, como observado no ritual Shipibo-Conibo denominado de Anishati ou Ani Sheati (MADEIRA, 2006; PAREDES PIQUE, 2004; RANGEL, 1999; RIVIÈRE, 2013), enquanto que os rituais masculinos se caracterizam por um conjunto de provações físicas e emocionais que podem englobar atividades como pisar em brasas, inscrever tatuagens, perfurar partes do corpo, se submeter a diversas formas de dor e medo, como por exemplo, levar picadas de formigas, conforme observado durante o Waumat dos Sateré-Mawé, conhecido como "ritual da tocandira" (ALVAREZ, 2005; RANGEL, 1999).

Vários autores, ao relacionar as tangas a rituais de puberdade, se apoiam na analogia com um ritual, registrado entre os Chama, que parece incompatível à nossa noção estereotipada de conforto. Durante este ritual, as meninas tinham o seu clitóris e lábios vaginais cortados por uma mulher mais velha e, após isto, eram defloradas com um pênis de argila, ficando, posteriormente, reclusas por um mês enquanto usavam um tapa-sexo oval de cerâmica (STEWARD e MÉTRAUX, 1948: 585). Será que as nossas noções hegemônicas sobre conforto, estabelecidas socialmente e culturalmente, são úteis para atribuirmos o uso das tangas às mulheres, ao passo que descartamos o seu uso por homens, como propuseram Prous e Lima (2011)?

\section{CONFRONTANDO OS DADOS}

Com o objetivo de confrontar as generalizações discutidas até aqui foi realizado um levantamento com base em relatórios de escavações, dissertações e teses, livro e artigos visando sistematizar os contextos disponíveis (HARTT, 1885; HILBERT, 1952; FARABEE, 1921; FERREIRA PENNA, 1877; LANGE, 1914; MEGGERS e EVANS, 1957; MORDINI, 
1929; NETTO, 1885; PALMATARY, 1950; ROOSEVELT, 1991; SCHAAN, 1997, 2004; TROUFFLARD, 2010). Neste levantamento foram identificadas 23 ocorrências que registram, de forma mais ou menos detalhada, o contexto de deposição das tangas, incluindo, quando possível, o tipo de urna na qual estava depositada e os materiais associados, além do sítio de procedência.

Diante disto, foram identificadas diferentes ocorrências de tangas em sepultamentos, encontradas nos seguintes arranjos funerários: junto ou no fundo das urnas, sob os ossos; dentro de urnas com um ou mais de um indivíduo, havendo casos de mais de uma tanga por urna; dentro de urnas simples maiores que abrigam outra urna, no espaço entre elas; do lado de fora junto às urnas, sozinhas ou junto com pratos e tigelas; do lado de fora, ao lado das urnas, em sepultamentos diretos no solo.

Quando depositadas dentro de urnas podem estar associadas a ossos humanos e de animais pintados de vermelhos, fragmentos cerâmicos diversos, aparentemente quebrados intencionalmente, tigelas, em alguns casos, estatuetas-chocalho, entre outros. Podem estar dentro de grandes urnas pintadas, grandes urnas simples, urnas com outras urnas em seu interior ou em urnas com outros recipientes no interior, dentro das urnas antropozoomorfas do estilo Pacoval (ver figura 3c), de urnas com excisões e figuras modeladas (ver figura 3b), e em vários tipos de urnas Joanes Pintado (ver figura 3a). Isto mostra que existe uma variabilidade muito maior no que diz respeito à sua forma de deposição nos sepultamentos, nem sempre aparecendo depositadas em urnas funerárias. Além disto, não necessariamente, eram sempre depositadas em urnas com características iconográficas compreendidas como femininas, algumas, inclusive, eram urnas simples, apenas engobadas de vermelho. 

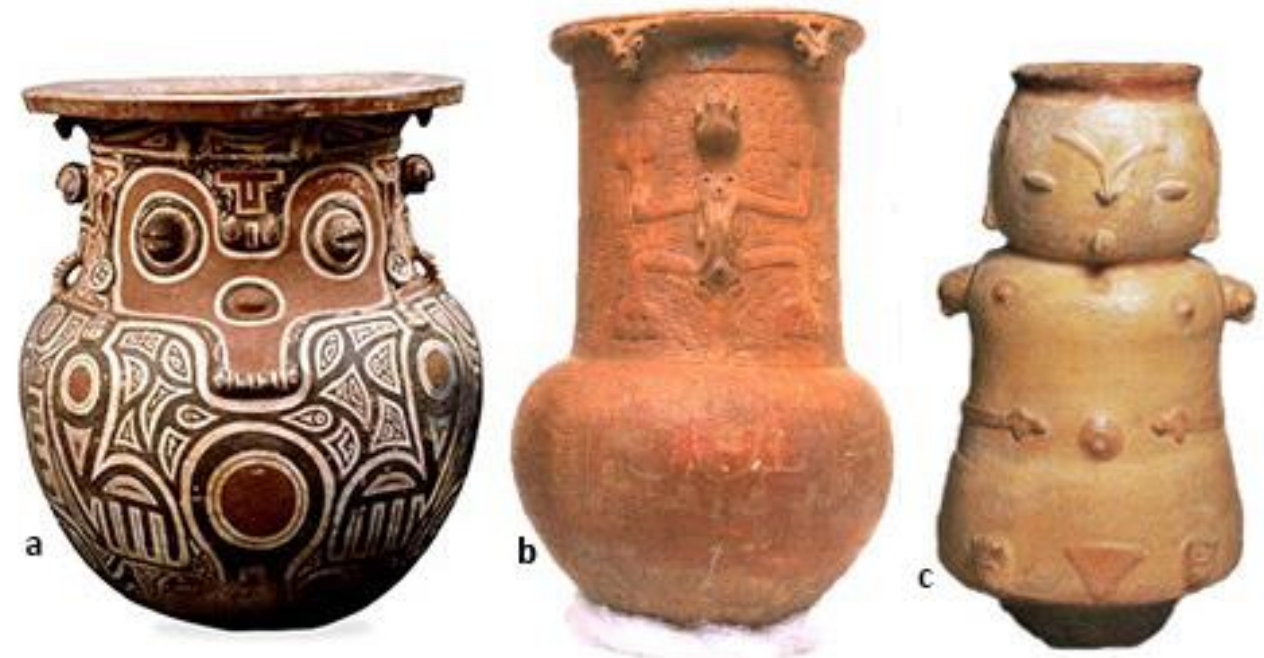

Figura 3. Variabilidade de tipos de urnas funerárias às quais as tangas aparecem associadas.

3a. Urna do tipo Joanes Pintado. Este tipo de urna, às vezes, tem os seus atributos iconográficos associados a algumas características femininas, de modo que, por exemplo, o círculo central em seu ventre é associado a um útero. Acervo do museu Paraense Emílio

Goeldi/ MCTI, Belém.

Fonte: Barreto, 2016

3b. Urna do tipo Ariri Exciso vermelho, que apresenta excisões e figuras modeladas, muitas vezes, aludindo a figuras de lagartos ou jacarés. Acervo Museu Nacional, Rio de Janeiro.

Fonte: Barreto, 2009.

3c. Urna do Estilo Pacoval. Os atributos iconográficos deste tipo de urna, como mamilos e o triângulo modelado entre as suas pernas, frequentemente, tem sido associados a características femininas. Acervo do Museu Etnológico de Berlim.

Fonte: Schaan, 2001a.

Além disto, este levantamento trouxe alguns dados sobre a identificação do sexo dos indivíduos acompanhados por tangas em sepultamentos. Das 23 ocorrências mencionadas acima, dentre aquelas com a presença de remanescentes ósseos humanos acompanhados por tangas, apenas em quatro casos houve a identificação do sexo dos indivíduos, sendo um deles um contexto bastante ambíguo, caracterizado pela presença de vestígios ósseos de um homem e de uma mulher. Nos outros três casos, uma mulher foi identificada, e nos outros dois casos, homens (ver tabela 1). 


\begin{tabular}{|c|c|c|c|c|c|c|c|}
\hline \multicolumn{2}{|c|}{ Dados referentes à identificação do sexo de vestígios ósseos associados a tangas escavados em } \\
sepultamentos
\end{tabular}

Tabela 1. Tangas encontradas em urnas funerárias, associadas a vestígios ósseos que tiveram o seu sexo estimado.

Betty Meggers e Clifford Evans escavaram uma urna que continha os ossos de um indivíduo do sexo feminino e outro do sexo masculino acompanhados por uma tanga vermelha que não foi possível determinar se foi sepultada com a mulher ou com o homem (MEGGERS e EVANS, 1957, p. 273). Estes arqueólogos escavaram também uma urna funerária do estilo Joanes Pintado em cujo interior havia uma tanga com grafismos associada a fragmentos de osso humanos que foram identificados como pertencentes a um indivíduo do sexo feminino (MEGGERS e EVANS, 1957:285). Já na década de 1970, José

\begin{tabular}{|l|l|l|l|l|l|l|}
\hline (C) Rev. Arqueologia Pública & Campinas, SP & v.13 & n.1 & p. & Jul/2019 & ISSN 2237-8294
\end{tabular}


Seixas Lourenço, professor da Universidade Federal do Pará, escavou no Teso dos bichos um sepultamento em uma urna que continha uma tanga com grafismos, uma estatueta e o crânio de um indivíduo que, posteriormente, foi identificado por Anna Roosevelt como masculino (ROOSEVELT, 1991: 393). Além disto, nos anos 80, foi feita uma doação, ao Museu Paraense Emílio Goeldi, pelo casal Errold McPhee e Graciete Lobato McPhee, de um crânio que foi encontrado dentro de uma urna Joanes Pintado acompanhado por uma tanga com grafismos, em um teso na Fazenda São Marcos, e que foi identificado pela bioarqueóloga Cláudia Cunha (comunicação pessoal, 2016) como um indivíduo do sexo masculino.

Até aqui, as atribuições de sexo e gênero, que relacionavam o uso das tangas às mulheres, estiveram relacionadas a ideias enviesadas do tipo "as tangas eram usadas por mulheres por que a sua forma triangular evoca ao delta feminino", ou por que "são encontradas dentro de urnas com características iconográficas femininas", ou por que "as características iconográficas femininas das urnas coincidem com o sexo dos vestígios ósseos sepultados nelas". Estas generalizações, ao longo das décadas, foram assumidas como verdades pelos arqueólogos e, com isto, as tangas passaram a ser compreendidas como índices da presença feminina em sepultamentos ou em áreas específicas dos sítios arqueológicos (Hartt, 1876; Meggers e Evans, 1957; Netto, 1885; Palmatary, 1950; Schaan, 2003, 2004). Os poucos dados contextuais, no entanto, não apoiam estes argumentos, levando a novas implicações interpretativas.

\section{IMPLICAÇÕES INTERPRETATIVAS}

As tangas cerâmicas têm sido interpretadas, há quase um século e meio, como objetos de uso exclusivo de mulheres. Conforme apontado ao longo deste artigo, as primeiras interpretações arqueológicas, no século XIX, consideraram algumas características morfológicas, sobretudo, a sua forma triangular, para associá-las ao corpo feminino, mais especificamente ao delta pubiano feminino (HARTT, 1876), de modo que estes objetos passaram a ser percebidos como uma espécie de característica diagnóstica para a identificação de sepultamentos femininos, o que era respaldado pela suposição de que as tangas eram sempre encontradas dentro de urnas funerárias com características iconográficas femininas (NETTO, 1885). 
As interpretações recentes têm esbarrado na falta de dados contextuais sobre as tangas. De fato, os ossos humanos, associados a tangas, depositados no interior das urnas funerárias, muitas vezes não puderam ser analisados para estimar o sexo em virtude do seu mal estado de preservação (SCHAAN, 2004). Diante disto, as interpretações sobre as tangas têm sido construídas com base em informações disponíveis na literatura.

Estas informações têm sido empregadas de forma acrítica e não muito reflexiva. Assim, diante da falta de dados contextuais, as deduções se valem de interpretações baseadas em estereótipos de gênero que vem sendo reproduzidos desde os primórdios da Arqueologia em Marajó, sem considerar o contexto onde foram formatadas. Schaan (2003), por exemplo, considerou que determinados tipos de tangas eram usados por mulheres mais velhas se apoiando em um caso registrado por Meggers e Evans (1957) em que uma tanga foi escavada com os ossos de um indivíduo cujo sexo foi estimando com base na generalização de que tangas são sempre encontradas com vestígios ósseos femininos. Deste modo, até o presente momento, as interpretações arqueológicas referentes às tangas partem dos mesmos velhos argumentos retrabalhados com uma nova camada de verniz.

Os poucos dados disponíveis hoje mostram que não, necessariamente, as tangas estão sempre associadas a sepultamentos femininos. Quais são então as implicações interpretativas disto? Ao longo deste artigo foi demonstrado como as tangas cerâmicas marajoara foram associadas a mulheres com base em generalizações e sem dados de contextos. Cabe enfatizar que a teoria Queer tem demonstrado que gênero é uma característica mutável, culturalmente construída, independentemente de órgão sexual, fluídos corporais e capacidade de reprodução. Diante disto, os indivíduos do sexo masculino associados a tangas cerâmicas, nos contextos comentados, estariam relacionados a indivíduos que rompem com a relação sexo-gênero, ou seja, que desempenham papéis de gênero opostos ao sexo biológico?

Interpretações enviesadas, muitas vezes baseadas em valores hegemônicos relacionados ao corpo feminino e masculino e a noções de conforto, e a reprodução destas interpretações de modo acrítico, além da falta de dados contextuais, estão por trás da generalização que relaciona tangas cerâmicas a mulheres. Deste modo, sugerir que os vestígios ósseos de indivíduos do sexo masculino acompanhados por tangas seriam de homossexuais, transgêneros, etc, seria assumir que as tangas são atributos diagnósticos do

\begin{tabular}{|l|l|l|l|l|l|l|}
\hline (C) Rev. Arqueologia Pública & Campinas, SP & v.13 & n.1 & p. & Jul/2019 & ISSN 2237-8294 \\
\hline
\end{tabular}


gênero feminino. Ou seja, as generalizações criticadas aqui estariam sendo reproduzidas mesmo sem dados indicativos. Então, se não há dados para relacionar as tangas ao gênero feminino e é premeditado associá-las a indivíduos que desempenham papéis de gênero opostos ao seu sexo biológico, como deve ser interpretada esta aparente variabilidade relacionada ao sexo dos indivíduos acompanhados por tangas?

$\mathrm{Na}$ Arqueologia, a crítica proveniente dos desdobramentos da teoria queer tem recaído nas interpretações estereotipadas sobre sexo, gênero e sexualidade do passado que raramente são sustentadas por evidências (AIMERS E RUTECKI, 2016; WICHERS et al, 2018). Assim, por exemplo, tem sido sugerido que estereótipos de gênero e de sexo podem ser questionados quando o arqueólogo considera a variabilidade dos artefatos e as suas características peculiares a fim de compreender o que esta variabilidade pode significar, bem como as dinâmicas sociais envolvidas nela (VOSS e SCHMIDT, 2000; WICHERS et al, 2018).

A variabilidade em relação ao tratamento cromático, morfologias e dimensões das tangas foi utilizada para estruturar hipóteses sobre gênero, idade e status social e também sobre a sua adaptação ao corpo feminino (RODRIGUES et al, 2001; SCHAAN, 2003, 2004). Estas características, no entanto, dentro da dimensão da variabilidade artefatual, poderiam dizer respeito a diferenças regionais ou cronológicas, ou ainda poderiam ter sido estruturadas socialmente, como é possível observar a partir da produção daquilo que é conhecido na literatura como pubic covering, isto é, coberturas pubianas (por exemplo, STEWARD, 1948), entre diversos grupos ameríndios amazônicos, a exemplo dos Wajana, cuja fabricação de tangas de tecido está socialmente imbrincada, podendo apresentar uma notada variabilidade em função do sexo e da idade de quem usará a peça e da atividade na qual será usada, ou seja, se será utilizada em cerimônias ou durante o cotidiano (VELTHEM, 2003). A partir dos poucos dados levantados se pode sugerir que as tangas eram objetos relacionados à corporificação de identidades tanto de mulheres quanto de homens. No entanto, para compreender as dinâmicas sociais envolvidas nesta variabilidade seria necessária a análise de amplos dados contextuais e estratigráficos.

As interpretações arqueológicas que consideram as tangas como femininas, estabelecidas a partir do fim do século XIX, e ainda hoje reproduzidas, são sustentadas por uma ideia hegemônica de corpo que é orientada pelos binarismos masculino/ feminino e homem/mulher, que dita como os corpos devem ser e como devem ser construídos. É 
importante ressaltar que os arqueólogos Pós-Processualistas há décadas chamam a atenção ao fato de como as nossas interpretações podem ser enviesadas por nossos valores atuais (HODDER, 2008; SHANKS, 2008; TILEY E SHANKS, 1987), e neste sentido, a atribuição das tangas a mulheres não estaria contaminada por nossas concepções cisheteronormativas que consideram o que é uma vestimenta de homem e uma de mulher?

\section{REFERÊNCIAS BIBLIOGRÁFICAS}

AIMERS, James e RUTECKI, Dawn M. Brave New World: interpreting sex, gender, and sexuality in the past. The SAA Archaeological Record, 16, 1:12-17, 2016.

ALBERTI, Benjamin. Los cuerpos en Prehistória: Más allá de la división entre sexo/género. Revista do Museu de Arqueologia e Etnologia, São Paulo, Suplemento 3: 57-67, 1999.

ALVAREZ, Gabriel O. O Ritual da Tocandira entre os Sateré-Mawé: Aspectos simbólicos do Waumat. Série Antropológica. Departamento de Antropologia, UnB, ㄲo 369. Brasília, 2005.

BARATA, Frederico. Artes plásticas no Brasil: Arqueologia. Rio de Janeiro: Edições de ouro, 1968.

BARRETO, Cristiana. Simbolismo sexual na antiga Amazônia. Revisitando urnas, estatuetas e tangas marajoara. In: Antes: histórias da pré-história. Catálogo de exposição. Rio de Janeiro: Centro Cultural Banco do Brasil, 2004

BARRETO, Cristiana. Meios místicos de reprodução social: arte e estilo na cerâmica funerária da Amazônia antiga. São Paulo: Museu de Arqueologia e Etnologia. Universidade de São Paulo (Tese de Doutorado Programa de pós-graduação em Arqueologia), Universidade de São Paulo, 2009.

BARRETO, Cristiana. O que a cerâmica marajoara nos ensina sobre o fluxo estilístico na Amazônia? In: BARRETO, Cristiana; LIMA, Helena; BETANCOURT, Carla Jaimes (Org.). Cerâmicas arqueológicas da Amazônia: rumo a uma nova síntese. Belém: Instituto do Patrimônio Histórico do Pará/ Museu Paraense Emílio Goeldi, p. 115-124, 2016.

BUTLER, Judith. Problemas de gênero: feminismo e subversão de identidade. Rio de Janeiro: Civilização Brasileira, 2013.

CARDOSO, José Luís. Símbolos sexuais do povoado pré-histórico de Leceia (Oeiras). Estudos Arqueológicos de Oeiras, 5, Oeiras, Câmara Municipal, pp. 251-261, 1995.

CONKEY, Margaret W. The structural analysis of Paleolithic art. In: LAMBERGKARLOVSKY (ed.). Archaeological thought in America. Cambridge: Cambridge University Press, 1989.

FARABEE, William. C. Explorations at the Mouth of the Amazon. In: Museum Journal 12: 142-161, 1921. 
FERREIRA PENNA, Domingos S. Apontamentos sobre os Cerâmios do Pará. Archivos do Museu Nacional do Rio de Janeiro, 2 , 47-67, 1877.

FIGUEIREDO, Napoleão. Arte amazônica, IV: As "tangas" do Marajó. São Paulo: Habitat, №30, 1956 .

FOUCAULT, Michel. Microfísica do poder (1979). Rio de Janeiro: Graal, 2007. GELLER, Pamela L. Identity and Difference: Complicating Gender in Archaeology. Annu. Rev. Anthropol, 38:65-81, 2009.

GONTIJO, Fabiano de S.; SCHAAN, Denise P. Sexualidade e Teoria Queer: Apontamentos Para a Arqueologia e Para a Antropologia Brasileiras. Revista de Arqueologia, volume 30, n. 2, pp.51-70, 2017.

HARTT, Charles. F. The Ancient Indian Pottery of Marajo, Brazil. American Naturalist, 5 (5), 259-27, 1871.

HARTT, Charles. F. Notas sobre algumas Tangas de Barro Cozido dos Antigos Indígenas da llha de Marajó. Archivos do Museu Nacional do Rio de Janeiro, 1876.

HARTT, Charles. F. 1885. Contribuições para a Ethnologia do Valle do Amazonas.

Archivos do Museu Nacional do Rio de Janeiro, v. 6, p. 1-174, 1885.

HILBERT, P. PAUL. Contribuição à arqueologia da ilha de Marajó: os "tesos" marajoaras do alto Camutins e a atual situação da ilha do Pacoval, no Arari. Belém: Instituto de Antropologia e Etnologia do Pará, Instituto de Antropologia e Etnologia do Pará. Publicação, $5,1952$.

HODDER, lan. Theory and Practice in Archaeology. Londres: Routledge, 2008.

LANGE, ALGOT.The Lower Amazon. New York: Putnam, 1914.

MARQUETTI, Flávia Regina; FUNARI, Pedro Paulo Abreu. Reflexões sobre o falo e o chifre: por uma arqueologia do masculino no Paleolítico. Dimensões, vol. 26, p. 357-371, 2011.

MEGGERS, Betty; EVANS, Clifford. Archaeological Investigations at the Mouth of the Amazon. Bureau of American Ethnology, Bulletin 167. Smithsonian Institution Press, 1957.

MORDINI, ANTONIO. I 'couvre sexe' precolombiani in argilla dell'isola de Marajó. Firenze: Archivio per l'Antropologia e l'Etnologia, v.59, pp.41-46, 1929.

NETTO, Ladislau. Investigações sobre a archeologia brazileira. Rio de Janeiro: Archivos do Museu Nacional do Rio de Janeiro, vol.6, pp. 257-554, 1885..

NOBRE, Emerson. Objetos e imagens no Marajó antigo: agência e transformação na iconografia das tangas cerâmicas. Dissertação (Mestrado em Arqueologia) - Museu de Arqueologia e Etnologia, Universidade de São Paulo, São Paulo, 2017.

PALMATARY, Hellen.C.The pottery of Marajo Island, Brazil. Philadelphia: Transactions of the American Philosophical Society 39 (3), 1950. 
PAREDES PIQUE, Susel. "Invisible entre sus árboles. Derechos humanos de las mujeres indígenas amazónicas del Perú: el caso de las aguarunas, asháninkas y shipibas". Flora Tristán: Lima, 2004.

POMBO, Mariana Ferreira. Desconstruindo e subvertendo o binarismo sexual e de gênero: apostas feministas e queer. Periódicus. Salvador, n. 7, v. 1 maio.-out., p. 388-404, 2017.

PROUS, André; LIMA, Ângelo Pessoa. De Cobras e Lagartos: as tangas marajoaras. Revista do Museu Arqueologia e Etnologia, São Paulo, n. 21, p. 231-263, 2011.

PROUS, André. 2013. Tangas of the Marajó (Brazil): ornamental pubic covers, their typology and meaning. Antiquity, Vol. 87, Issue 337, p.815, 2013.

RANGEL, Lucia Helena. Da infância ao amadurecimento: uma reflexão sobre rituais de iniciação. Interface - Comunicação, Saúde, Educação, n35, p.147-52, 1999.

RODRIGUES, Igor et al. Fabricação e utilização experimentais de réplicas de tangas marajoara. Revista do Museu Arqueologia e Etnologia, São Paulo, n. 21, p. 265-274, 2011.

ROOSEVELT, Anna C. Interpreting Certain Female Images in Prehistoric Art. In: Miller, V. (org). The Role of Gender in Precolumbian Art and Architecture. Harvard: University Press, p.1-34, 1988.

ROOSEVELT, Anna C. Moundbuilders of the Amazon: Geophysical Archaeology on Marajo Island, Brazil. San Diego: Academic Press, 1991.

RIVIÈRE. Claude. Socioantropologia das religiões. São Paulo: Ideias \& Letras, 2013.

SCHAAN, Denise. P. into the labyrinths of Marajoara pottery: status and cultural identity in an Amazonian complex society. In: MCEWAN, C et al (orgs.). The Unknown Amazon.

Nature in culture in ancient Brazil. Londres: British Museum Press, pp. 108-133, 2001a.

SCHAAN, Denise. P. Estatuetas antropomorfas marajoara: o simbolismo de identidades de gênero em uma sociedade complexa amazônica. Boletim do Museu Paraense Emílio Goeldi. série Antropologia, 17(2), 2001b.

SCHAAN, Denise. P. A ceramista, seu pote e sua tanga: identidade e papéis sociais em um Cacicado Marajoara. Revista Arqueologia, 16: 31-45, 2003.

SCHAAN, Denise. P. The Camutins Chiefdom: Rise and Development of Social Complexity on Marajó Island, Brazilian Amazon. Tese de doutorado. Pittsburg: Universidade de Pittsburgh, 2004.

SHANKS, Michel. 1133-144. Post-processual archaeology and after. In: BENTLEY, R.A.; MASCHNER, H. D. G. e CHIPPINDALE, C. Handbook of Archaeological Theories . Lanham: AltaMira Press, 2008.

SHANKS, M. e TILLEY. C. Reconstructing archaeology: Theory and practice. London: Routledge, 1987. 
SILVA, Janaíne Januário; CORREIA, Maria das Graças dos Santos. A idealização da figura feminina na obra Iracema de José de Alencar. Revista LitCult, Vol.13, 1ํsemestre, 2017.

SILVA, Maria do Carmo Couto da. Representações do índio na arte brasileira do século XIX. Revista de História da Arte e Arqueologia, v. 8, p. 63-71, 2007.

STEWARD, Julian H. Handbook of South American Indians. Volume 3. The Tropical Forest Tribes, 1948.

STEWARD ,Julian H.; MÉTRAUX, Alfred. Tribes of the Peruvian and Ecuadorian Montaña. In: STEWARD, Julian H. (ed.). Handbook of South American Indians. Volume 3. The Tropical Forest Tribes. Washington DC: Smithsonian Institution, p. 535-656, 1948.

TROUFFLARD, Joanna. Testemunhos funerários da Ilha de Marajó no Museu Dr. Santos Rocha e no Museu Nacional de Etnologia. Interpretação arqueológica. Dissertação de mestrado. Lisboa: Faculdade de Ciências Sociais e Humanas, Universidade Nova de Lisboa, 2010.

UGALDE, María Fernanda. De siamesas y matrimonios: tras la simbología del género y la identidad sexual en la iconografía de las culturas precolombinas de la costa ecuatoriana. In:

USILLOS, Andrés Gutierres (coordenador). Trans. Diversidad de identidades y roles de género, Quito: Museo, p.100-110, 2018.

VELTHEM, Lucia. Hussak Van. O belo é a fera: a estética da produção e da predação entre os Wayana. Lisboa: Museu Nacional de Etnologia: Assírio \& Alvim, 2003.

VOSS, Barbara L.; SCHMIDT, Robert A. Archaeologies of sexuality: An introduction. Archaeologies of sexuality. In VOSS, Barbara L.; SCHMIDT, Robert A. Archaeologies of sexuality. Londres: Routledge, p.1-32, 2000.

WICHERS, Camila M. et al. Interview with Barbara Voss Gender Issues. Revista Habitus Revista do Instituto Goiano de Pré-História e Antropologia, Goiânia, v. 16, n. 1, p. 187-204, jun. 2018. 